\title{
Flurbiprofen loaded ethosomes - transdermal delivery of anti-inflammatory effect in rat model
}

\author{
Sarvesh Paliwal', Amita Tilak', Jaiprakash Sharma², Vivek Dave ${ }^{1 *}$ (D) Swapnil Sharma ${ }^{1}$, Renubala Yadav ${ }^{1}$, \\ Saraswati Patel', Kanika Verma' and Kajal Tak
}

\begin{abstract}
Background: Ethosomes have been widely used in Transdermal Drug Delivery System (TDDS) as they increase the permeation of drug across the skin.

Methods: Flurbiprofen loaded vesicular ethosomes were formulated, optimized and characterized for particle size, entrapment efficiency, poly dispersive index (PDI), microscopy using Atomic force microscopy (AFM), Scanning electron microscope (SEM) and Transmission electron microscopy (TEM) and Interaction of drug and excipients were studied using Fourier transform infra-red (FTIR) spectroscopy, Differential scanning colorimetry (DSC), Thermo gravimetric analysis (TGA). Further, ethosomal formulations of flurbiprofen were evaluated for stability study of three months and in vitro drug permeation study was carried out using albino rat skin. In addition, skin irritation test was evaluated by Draize test and in vivo study of prepared formulation was examined through paw edema assay by inducing carrageenan and cold plate method.
\end{abstract}

Results: Amongst all formulations, EF5 formulation exhibited ideal surface morphology, with maximum entrapment efficiency (95\%) with optimal excipient concentration i.e. $200 \mathrm{mg}$ phospholipid and 35\% ethanol. The ideal vesicle size was achieved as $162.2 \pm 2 \mathrm{~nm}$, with zeta potential $-48.14 \pm 1.4 \mathrm{mV}$ with the PDI of 0.341 . In-vitro permeation study shows a release of $82.56 \pm 2.11 \mathrm{~g} / \mathrm{cm}^{2}$ in $24 \mathrm{~h}$ and transdermal flux was found as $226.1 \mathrm{\mu g} / \mathrm{cm}^{2} / \mathrm{h}$. Cold plate test indicates that the formulation EF5 showed a marked analgesic activity and Carrageenan induced paw edema test indicates that the formulation EF5 inhibits the increase in paw edema. Ethosomal suspension at $4{ }^{\circ} \mathrm{C}$ showed maximum stability.

Conclusions: The overall study concluded that this ethosomal approach offers a new delivery system for sustained and targeted delivery for flurbiprofen.

Keywords: Ethosomes, Flurbiprofen, Transdermal delivery

\section{Background}

Transdermal drug delivery system (TDDS) offers many advantages in the modern drug therapy and uses skin as possible route for drug administration to attain systemic effect. Transdermal patches regulate the delivery of drugs by engaging a suitable combination of hydrophilic and lipophilic polymers. Ethosomes has been reported as

\footnotetext{
* Correspondence: vivekdave1984@gmail.com

1Department of Pharmacy, Banasthali Vidyapith, Banasthali, Rajasthan 304022, India

Full list of author information is available at the end of the article
}

the novel innovative passive, noninvasive delivery carriers for lipid based system with attractive features.

Ethosomes carriers were first reported by Touitou and her colleagues in 2000. These are spongy, soft and malleable vesicles modified for improved drug delivery of active agents. Generally, ethosomes which are phospholipid vesicular system have lipid bilayers like liposomes. Ethosomes are composed of phospholipids, high concentration of ethanol and water whereas liposomes composition uses cholesterol instead of ethanol. Ethanol as an important adjuvant exhibits impressive transdermal permeability enhancing properties and also

(C) The Author(s). 2019 Open Access This article is distributed under the terms of the Creative Commons Attribution 4.0 International License (http://creativecommons.org/licenses/by/4.0/), which permits unrestricted use, distribution, and 
results in softening of ethosomal lipid bilayer. Therefore, the presence of ethanol in ethosomes formulation offers rapid permeation of entrapped drug molecules through skin. Additionally, it results in steady state flux (approximately $1 \mathrm{mg} / \mathrm{cm}^{2} / \mathrm{h}$ ) across skin in comparison to liposomes which remain confined to the upper layer of stratum corneum [1]. The mechanism for enhanced pervasion of drug into deeper skin layers from ethosomes is still not well understood. However, the enhanced permeability of ethosome carriers is possibly related to the collective mechanism between high concentration of ethanol, phospholipids vesicles and skin lipids. Ethanol act together with lipid molecules in the polar head group region ensuing in increased fluidity and resulting in increased membrane permeability. Ethosomes have been considered as improved form of liposomes [2]. In different studies ethosomes have been used widely as a carrier system for topical administration. Various reports have reported that ethosomes have increased drug deliveries across skin both at in vitro and in vivo level, such as Ketoprofen, Testosterone, Cannabidiol, Buspirone hydrochloride, Erythromycin, Ammonium glycyrrhizinate, Ibuprofen, Benzocaine, Fluconazole, Finasteride, Lamivudine and 5-aminolevulinic acid. Interestingly, ethosomes preparation does not require special equipment's and thus is considered easy to formulate. Discovery of ethosomes has started a new revolution in vesicular research for transdermal drug delivery.

Flurbiprofen, a non-steroidal anti-inflammatory drug which is phenylalkanoic acid derivative exhibits antipyretic, anti-inflammatory and analgesic activities. Oral formulations of flurbiprofen are indicated in acute or chronic symptomatic treatment of rheumatoid arthritis, osteoarthritis and anklylosing spondylitis. It is also useful in pain reduction concomitant with dysmenorrhea and in bursitis, tendonitis and soft tissue trauma. Flurbiprofen is the most potent non-steroidal anti-inflammatory agent which reversibly inhibits cyclooxygenase (COX), an enzyme accountable for metabolism of arachidonic acid. The cyclooxygenase (COX) inhibition decreases prostaglandin production, preferably the highly pruritic PGE2 and PEG2 [3].

In view of this, in the present work, we have entrapped flurbiprofen in the lipid bilayers of ethosomes to develop sustained transdermal delivery of ethosomal gel of flurbiprofen and evaluated its performance using in vitro and in vivo models.

\section{Methods}

\section{Materials}

Flurbiprofen was purchased as a gift sample from Lupin Research Park, Pune, India. Soya Phosphatidylcholine, ethanol, chloroform, propylene glycol, isopropyl alcohol and methanol were purchased from Sigma-Aldrich chemicals, Germany. Carbopol $934 \mathrm{~K}$ was received from Himedia laboratory Mumbai, India. All other chemicals used during the experiment were of analytical grade.

\section{Methods}

\section{Preparation of flurbiprofen loaded ethosomes}

Flurbiprofen loaded ethosomes were prepared through the method discussed by Touitou (2000). The formulations for ethosomal system of flurbiprofen were prepared using $100 \mathrm{mg}, 200 \mathrm{mg}, 300 \mathrm{mg}$ phospholipids, 30, 35, $40 \% \mathrm{w} / \mathrm{w}$ of ethanol, $250 \mathrm{mg}$ flurbiprofen (API), $1 \%$ propylene glycol (PEG) and water (\%) to q.s., depicted in Table 1. Initially, ethanol and propylene glycol was used to dissolve the drug and phospholipid and the solution was allowed to heat at temperature of $30^{\circ} \mathrm{C}$ on water bath. Further distilled water was added steadily as a fine stream to the solution with continuous stirring using magnetic stirrer (Remi equipment, Mumbai) at the speed of $700 \mathrm{rpm}$ in a closed vessel. Then prepared solution was maintained at the temperature of $4{ }^{\circ} \mathrm{C}$. Afterwards sonication was done by the means of probe sonicator for 3 cycles of $5 \mathrm{~min}$ (with $5 \mathrm{~min}$ ' rest between the cycles) [4]. Same protocol was followed for the Gliclazide ethosomal preparation by thin film hydration method which shows an improved choice for sustained release of drug through topical drug delivery [5].

\section{Flurbiprofen loaded ethosomal gel}

Carbopol $934 \mathrm{~K} 0.75 \% \mathrm{w} / \mathrm{v}$ was immersed in small amount of water for an hour. With continuous stirring, $20 \mathrm{ml}$ of ethosomal suspension containing flurbiprofen $(250 \mathrm{mg}$ ) was added to the swollen polymer. Stirring was continued at the speed of $700 \mathrm{rpm}$ in a closed vessel to achieve homogeneous ethosomal gel consistency at temperature of $30^{\circ} \mathrm{C}$. Triethanolamine (TEA) was added to neutralize the $\mathrm{pH}$ with slow stirring until the gel was formed. The $\mathrm{pH}$ of the semisolid ethosomal gel formulations was measured by using $\mathrm{pH}$ meter [6].

\section{Physicochemical characterization of flurbiprofen loaded ethosomal system}

Particle size, zeta potential and Polydispersive index (PDI)

The characteristics like average size, particle size distribution and surface charge of the formulated ethosomes were determined by dynamic light scattering (DLS)

Table 1 Composition of flurbiprofen containing ethosomes

\begin{tabular}{llllllllll}
\hline Composition & EF1 & EF2 & EF3 & EF4 & EF5 & EF6 & EF7 & EF8 & EF9 \\
\hline Drug (Flurbiprofen) mg & 250 & 250 & 250 & 250 & 250 & 250 & 250 & 250 & 250 \\
Soya lecithin (mg) & 100 & 100 & 100 & 200 & 200 & 200 & 300 & 300 & 300 \\
Ethanol (\%) & 30 & 35 & 40 & 30 & 35 & 40 & 30 & 35 & 40 \\
Propylene glycol (\%) & 1 & 1 & 1 & 1 & 1 & 1 & 1 & 1 & 1 \\
Water (\%) & q.s & q.s & q.s & q.s & q.s & q.s & q.s & q.s & q.s \\
\hline
\end{tabular}


using Malvern Zeta sizer Nano ZS (Malvern Instruments, UK) at room temperature. Ethosomal formulations were dispersed in HPLC water and an instrument was set at an angle of $90^{\circ}$ with a medium viscosity of 0.8862 and refractive index 1.361. The particle size distribution, poly dispersibility index and zeta potential were determined; all the measurements were made in triplicates [6].

\section{Morphology of Flurbiprofen loaded ethosomes by TEM, SEM, and AFM}

The morphology of prepared flurbiprofen loaded ethosomes was studied using Transmission electron microscopy (TEM) (AIIMS, Delhi) operated at $200 \mathrm{kV}$ at a magnification of 9900x. $20 \mu \mathrm{l}$ of the Flurbiprofen loaded ethosomal suspension was diluted with millipore water and was allowed to stain with $2 \% \mathrm{w} / \mathrm{v}$ phosphotungstic acid for about $30 \mathrm{~s}$. Sample was placed on coated copper grid and was allowed to dry. For every sample, two grids were prepared and randomly viewed [7].

Scanning electron microscopy (SEM) was performed using lyophilized sample fixed on carbon tape and palladium coating was done to provide the conductivity to the sample during the electron bombardment. Imaging was done using SEM (Banasthali Vidyapith, Rajasthan, India) performed at $20 \mathrm{kV}$ at magnification of $3300 \mathrm{x}$, 19,000x [8].

For atomic force microscopy (AFM) analysis, $1 \mathrm{ml}$ of ethosomal suspension was carefully placed on a neatly sliced mica sheet and left for incubation of five minutes. From the surface of mica sheet, unbound ethosomes were removed by rinsing with deionized water. Sample was air dried at normal room temperature and was scanned using Advance Integrated Scanning tool for Nano Technology (AIST-NT) Model: Smart SPM 1000, (NIIFP, Russia) in tapping mode. Every sample was scanned, at a resolution of $5 \mu \mathrm{m} \times 5 \mu \mathrm{m}$ and images were observed simultaneously by showing height, amplitude and phase signal of the cantilever in the trace direction.

\section{Attenuated total reflection fourier transforms infra-red spectroscopy (ATR-FTIR)}

Infrared spectra of pure drug (flurbiprofen), flurbiprofen loaded ethosomes, physical mixture soya lecithin and optimized ethosomal formulation were scanned by Bruker EQUINOX 55 FTIR spectrophotometer furnished by a liquid nitrogen cooled mercury cadmium telluride (MCT) detector at resolution of $2 \mathrm{~cm}^{-1}$. The internal reflection element (IRE) is made up of diamond with an incidence angle of $45^{\circ}$, the speed of scans rate was 32,21 resolutions leading to one internal reflection. An innovative attenuated total reflection (ATR) modification was applied to all spectrums, and the region of graph line was from 4000 to $400 \mathrm{~cm}^{-1}$ using ATR-FTIR Opus software.

\section{Raman spectroscopy}

Raman spectra of the flurbiprofen loaded ethosomes were scanned with a spectrophotometric system (Thermo-scientific instrument (DxRxi), equipped with a OMINICxi-Analysis software. The $532 \mathrm{~nm}$ laser beam was used to collect the spectra with the laser power of 5-100 $\mathrm{mW}$. A range of $125-4000 \mathrm{~cm}^{-1}$ was selected to scan and obtain entire spectrum.

\section{Differential scanning calorimetry (DSC)}

Flurbiprofen, soya lecithin, and lyophilized formulation EF5, were used for DSC (Model: DSC 204 F1 PHOENIK NETEZCH) analysis. The samples (drug, lipid and lyophilized ethosomes) were crimped placed and placed on aluminium pan and were crimped. Further, sample was heated and nitrogen was flowed $\left(30 \mathrm{ml} / \mathrm{min}\right.$ ) at a scanning rate of $5{ }^{\circ} \mathrm{C} / \mathrm{min}$ from $25^{\circ} \mathrm{C}$ to $300^{\circ} \mathrm{C}$. As a reference same quantity of indium on another aluminium pan was placed and scanned. For drug and drug loaded ethosomes, the range of temperature for heat flow was measured [9]. Afterwards, the scan were recorded and plotted on the graph, representing temperature and heat flow $(\mathrm{w} / \mathrm{g})$ on the $\mathrm{X}$-axis and $\mathrm{Y}$-axis respectively.

\section{Thermo gravimetric analysis (TGA)}

In order to study the various physicochemical properties, TGA studies of drug, lipid and lyophilized formulation were performed using TGA-4000 Perkin Elmer with Pyris Manager Software. First, crucible was weighed empty then sample was weighed in crucible and were kept back on the assembly which was made to run the sample. The scan was recorded and plotted graph showing percent weight loss on $\mathrm{Y}$-axis and temperature on $\mathrm{X}$-axis respectively $[10]$.

\section{Entrapment efficiency of ethosomes}

The \% entrapment efficiency (\%EE) of formulated ethosomes was calculated by subtracting the amount of un-entrapped drug by total amount of drug taken. Flurbiprofen amount was analyzed using centrifugation method i.e. by centrifuging the formulations by means of ultracentrifuge (Remi) equipped with TLA- 45 rotor at $14,000 \mathrm{rpm}$ at $4{ }^{\circ} \mathrm{C}$ for $30 \mathrm{~min}$. After first centrifugation supernatant was removed and re-centrifuged for $15 \mathrm{~min}$ at $14,000 \mathrm{rpm}$. The sum total of unentrapped flurbiprofen was examined using UV/Vis-spectrophotometer at $272 \mathrm{~nm}$. Each sample was evaluated thrice $[11,12]$. The percentage of encapsulated drug amount was calculated using the following formula: 
$\mathrm{EE}(\%)=($ Amount of the drug in the ethosomes

/Total amount of drug loaded into the ethosomes) $\times 100 \%$.

\section{Viscosity, $\mathrm{pH}$ and Spreadability}

The viscosity of the gel was observed by Brookfield viscometer (model LVDV II Pro) at $20 \mathrm{rpm}$ of fixed speed, and $\mathrm{pH}$ was monitored by digital $\mathrm{pH}$ meter. For the spreadibility measurement, prepared ethosomal formulation $(1 \mathrm{~g})$ was sandwiched between two glass slides having $8 \mathrm{~cm}$ length [13]. Then different weight was tied from the pulley and the weight at which the glass slide move and the time required to pull the upper slide and further spreading of gel to the lower slide was measured. The measurement of length of displaced slide was taken in triplicate and spreadability was calculated using to the described formula:

$$
\mathrm{S}=\mathrm{M} \times \mathrm{L} / \mathrm{T}
$$

Where, $\mathrm{S}$ represents the Spreadability of the gel, $\mathrm{M}$ is the weight knotted to the upper slide (g), L shows the distance moved by the slides $(\mathrm{cm})$ and $\mathrm{t}$ is the time taken by the upper slide to roll down.

\section{Skin irritation studies}

Draize patch test was performed to examine the irritancy of plain flurbiprofen solution and optimized formulation in Albino rats. Using the intact skin of Albino rats the irritation potential of flurbiprofen and EF5 was studied. Before $24 \mathrm{~h}$ of the start of the assay, dorsal hair of the animal was shaved. Animals were allocated into three groups (1st group- no drug, 2nd group- flurbiprofen, 3rd group- optimized formulation) having six animals $(n=6)$ in every group. Further, $2 \mathrm{ml}$ of flurbiprofen solution and EF5 were applied uniformly on the shaved skin of rats and any visible changes were observed at 24,48 , and $72 \mathrm{~h}$ and scored accordingly [14].

\section{In vitro skin permeation study}

To perform the in-vitro skin permeation test, male Albino Wistar rats (150-200 g) were used. Briefly, hair of dorsal region of rat were removed in an area of $2 \mathrm{~cm}^{2}$ of the skin using hair removal cream [15] (Anne French; Wyeth Ltd., Hyderabad, India). Further, rats were scarified by high dose of anesthesia and dorsal hair free skin was isolated. Subsequently, subcutaneous fat and connective tissues were neatly trimmed using sharp scissor. Later, the skin was washed with physiological salt solution (PSS) and then by distilled water top and placed in refrigerator at $4{ }^{\circ} \mathrm{C}$ in PBS for further use [16]. The in vitro drug permeation from flurbiprofen loaded ethosomal formulation was determined using Franz's diffusion cell technique, via rat skin considering it as semipermeable membrane. Digital micrometer was used to measure thickness of the skin which was found to be $2.8 \pm 0.7 \mathrm{~mm}$. Thereafter, skin was cautiously clamped with the Franz's diffusion cell having effective permeation area $\left(0.64 \mathrm{~cm}^{2}\right)$ and receptor volume $(10 \mathrm{ml})$ with use of phosphate buffer saline ( $\mathrm{pH} 7.4)$. Accurately weighed $1 \mathrm{~g}$ of the Flurbiprofen loaded ethosomal gel and transferred it to donar compartment of the Franz's diffusion cell, at a constant temperature i.e. $37 \pm 0.5^{\circ} \mathrm{C}$ was maintained with continuous stirring using magnetic stirrer (Expo India Ltd., Mumbai, India) at $200 \mathrm{rpm}$. At predetermined time intervals $(0.5,1,2,6,8, \ldots . .12,24 \mathrm{~h}$.$) , samples were withdrawn and$ to maintain the sink condition, instantly same volume of blank receptor fluid was added to the receptor compartment. HPLC method was further used to analyze the drug concentration. The experiment was performed in triplicates and expressed as the Mean \pm SD. For all ethosomal batches, in vitro skin permeation studies were accomplished [17]. All analysis was made in accordance with the standard institutional guiding principles duly proved by the Committee for the Purpose of Control and Supervision of Experiments on Animals (CPCSEA) of Banasthali University Animal Centre (Rajasthan, India).

\section{Data treatment}

The flux of the formulated flurbiprofen loaded ethosomes was calculated through the Fick's second law of diffusion, in which the total amount of drug $\left(\mathrm{Q}_{t}\right)$ appearing in the receptor compartment in time $t$ is expressed as:

$$
\begin{aligned}
\mathrm{Q}_{\mathrm{t}}= & \mathrm{AKLC}_{\mathrm{o}}\left[\left(\mathrm{D}_{\mathrm{t}} / \mathrm{L}^{2}\right)-(1 / 6)-\left(2 / \pi^{2}\right)-\epsilon\left((1-1)^{\mathrm{n}} / \mathrm{n}^{2}\right) 1\right) \\
& \left.\exp \left(\mathrm{D}^{\mathrm{n}} 2 \pi^{2} \mathrm{t} / \mathrm{L}^{2}\right)\right]
\end{aligned}
$$

Where,

$\mathrm{A}=$ effective diffusion area,

$\mathrm{C}_{0}=$ concentration of drug that remain constant in the vehicle,

$\mathrm{D}=$ diffusion coefficient,

$\mathrm{L}=$ thickness of the skin membrane and.

$\mathrm{K}=$ partition coefficient of the drug between membrane and the vehicle.

At steady state, Eq. (1) can represent as follows:

$$
\mathrm{Q} t=\mathrm{KLC}_{\mathrm{O}}\left[\left(\mathrm{D}_{\mathrm{t}} / \mathrm{L}^{2}\right)-(1 / 6)\right]
$$

Thus, the flux (J) was calculated through the slope of the equation to show steady state position of the amount of the drug permeated through an area with respect to a 
given time t. Hence, from Eq. (2), the flux (J) can be expressed as follows:

$$
\mathrm{J}=\mathrm{C}_{0} \mathrm{KD} / \mathrm{L}=\mathrm{C}_{0} \mathrm{Kp}
$$

Where, Kp is known the permeability coefficient [18].

\section{In vivo activity all}

animal experimental protocols were approved by Institutional Animal Ethical Committee (Ref. no. BU/3431/1617) and conducted in accordance to the Committee for the Purpose of Control and Supervision of Experiments on Animals (CPCSEA) guidelines. Male Wistar rats (weighing 250-300 g) and mice (weighing 20-30 g), were employed for the experiments. The rats were procured from Lala Lajpat Rai Veterinary and Animal Sciences, Hisar, India. They were kept in polyacrylic cages and maintained under standard housing conditions of temperature $\left(25 \pm 2{ }^{\circ} \mathrm{C}\right)$ and humidity $(60-65 \%)$ with 12-h light-dark cycles. They were acclimatized for one month and given ad libitum access to food (dry pellets) and water.

\section{Cold plate test}

Analgesic activity was assessed by measuring reaction time of rats at low temperature. Paw licking, jumping, defecation, urination, shivering was noted as latency of rats. Rats were divided in three different groups $(n=6)$ and received treatment as shown in experimental design (Table 2). Group I was subjected to Brugel $^{\circ}$ marketed preparation whereas animals of group II-III received different concentration of test formulations topically, respectively. For induction of pain, the rats were placed on cold plate $\left(4^{\circ} \mathrm{C}\right)$ and latencies of both forepaw licking (reaction time; cutoff time: 15-20 s) were measured for each animal using a stopwatch at a regular interval of 15 min till $1 \mathrm{~h}$ [19].

\section{Carrageenan induced paw edema}

Rats were divided in three groups $(n=6)$ and received treatment as shown in experimental design (Table 2). Acute edema was induced by injecting $0.1 \mathrm{ml}$ of freshly prepared $1 \%$ solution of carrageenan in sub-plantar tissue of rat right hind paw. After $30 \mathrm{~min}$ of induction, Brugel $^{\circ}$ marketed preparation was applied to animals of group I whereas group II and III animals received topical

Table 2 Experimental Design $(n=6)$

\begin{tabular}{ll}
\hline Group & Treatment \\
\hline$I$ & Brugel Gel \\
$\|$ & Etho $5(10 \mathrm{mg} / \mathrm{kg})$ \\
\|\| & Etho $5(20 \mathrm{mg} / \mathrm{kg})$ \\
\hline
\end{tabular}

application of test formulations (10 and $20 \mathrm{mg} / \mathrm{kg}$ ) respectively. Reduction in edema was measured at every $15 \mathrm{~min}$ up to $2 \mathrm{~h}$ using plethysmometer. Percent change in paw volume was calculated and expressed as the swelling index [19].

\section{Stability studies}

To determine the drug retention ability by the formulated ethosomal vesicles, stability studies were performed for three months at different temperature. The stability of vesicles is the major problem in the formulation of ethosomes because of leaching and drug accumulation properties in the lipid layers. The optimized formulation EF5 was selected for the stability studies. Two batches of lyophilized ethosomes and ethosomal suspension were divided and kept in sealed vials $(10 \mathrm{ml})$ at $4{ }^{\circ} \mathrm{C} / 60 \pm 5 \mathrm{RH}$ $(n=3)$ and at $25^{\circ} \mathrm{C} / 60 \pm 5 \mathrm{RH}$. As a function of time the sample were analyzed after 7, 15, 30, 60 and 90 days of storage (Table 3).

\section{Statistical analysis}

Statistical analysis results were calculated using a computer based, Graph Pad Prism version 5.1 software program. One-way ANOVA was used to statistically estimate the data with Tukey Posthoc test. $P$ values less than $0.05(p<0.05)$ considered statistically significant. All values were conveyed as the mean value \pm standard deviation.

\section{Results and discussion} Ethosomal formulation

Various ethosomal formulations have been reported for topical drug delivery for multiple diseases. Different formulations of flurbiprofen loaded ethosomes were formulated by varying the concentration of ethanol and soya lecithin (Table 1). Formulation EF1 to EF3 and formulation EF4 to EF6 contained constant amount of soya lecithin i.e. $100 \mathrm{mg}$ and $200 \mathrm{mg}$ respectively with varying in concentration of ethanol 30, 35 \& 40\% respectively. Similarly, formulation EF7 to EF9 had highest concentration of soya lecithin i.e. $300 \mathrm{mg}$ with varying in concentration of ethanol.

\section{Particle size, zeta potential, polydispersity index (PDI)}

Dynamic light scattering (DLS) technique was used to measure the particle size and polydispersity index (PDI), shown in Table 4. The mean particle size of all formulations was ranged between $162.2 \pm 2 \mathrm{~nm}$ to $191.0 \pm 8 \mathrm{~nm}$ and PDIs value was ranged between 0.341 to 0.498 . Above all formulation, EF5 exhibited the maximum encapsulation efficiency with mean particle size of $162.2 \pm 2 \mathrm{~nm}$ and a PDI of 0.341. Vesicle size play an important role in topical drug delivery systems as small size vesicles delivers their contents more efficiently across deeper layers of skin $[20,21]$. In our investigation formulated ethosomes 
Table 3 Stability study of optimized formulation EF 5

\begin{tabular}{|c|c|c|}
\hline Time (days) & Microscopic evaluation & \%Encapsulation efficiency \\
\hline \multicolumn{3}{|c|}{ Ethosomal suspension (EF 5) } \\
\hline \multicolumn{3}{|c|}{ At $4^{\circ} \mathrm{C} / 60 \pm 5 \mathrm{RH}(n=3)$} \\
\hline Initial & Smooth spherical vesicles & $95 \pm 1$ \\
\hline 7 & Smooth spherical vesicles & $91.5 \pm 2.3$ \\
\hline 15 & Smooth spherical vesicles & $88.4 \pm 3.2$ \\
\hline 30 & Smooth spherical vesicles & $85.4 \pm 1.2$ \\
\hline 60 & Rough spherical vesicles & $80.7 \pm 3.3$ \\
\hline 90 & Rough spherical vesicle & $74.5 \pm 1.4$ \\
\hline \multicolumn{3}{|c|}{ At $25^{\circ} \mathrm{C} / 60 \pm 5 \mathrm{RH}(n=3)$} \\
\hline Initial & Smooth spherical vesicles & $95 \pm 1$ \\
\hline 7 & Smooth spherical vesicles & $89.5 \pm 1.3$ \\
\hline 15 & Smooth spherical vesicles & $86 \pm 3$ \\
\hline 30 & Rough spherical vesicles & $73.7 \pm 1.8$ \\
\hline 60 & Agglomerate & $68.2 \pm 2$ \\
\hline 90 & Agglomerate & $54.5 \pm 1.4$ \\
\hline \multicolumn{3}{|c|}{ Lyophilized ethosomal suspension (EF5) } \\
\hline \multicolumn{3}{|c|}{ At $4^{\circ} \mathrm{C} / 60 \pm 5 \mathrm{RH}(n=3)$} \\
\hline Initial & Smooth spherical vesicles & $95 \pm 1$ \\
\hline 7 & Smooth spherical vesicles & $93.5 \pm 1.2$ \\
\hline 15 & Smooth spherical vesicles & $89.5 \pm 3.1$ \\
\hline 30 & Smooth spherical vesicles & $86.43 \pm 2$ \\
\hline 60 & Rough spherical vesicles & $80.3 \pm 1.2$ \\
\hline 90 & Rough spherical vesicles & $78.3 \pm 1.9$ \\
\hline \multicolumn{3}{|c|}{ At $25^{\circ} \mathrm{C} / 60 \pm 5 \mathrm{RH}(n=3)$} \\
\hline Initial & Smooth spherical vesicles & $95 \pm 1$ \\
\hline 7 & Smooth spherical vesicles & $88.4 \pm 1$ \\
\hline 15 & Rough spherical vesicles & $81.7 \pm 2.4$ \\
\hline 30 & Rough spherical vesicles & $77.9 \pm 3$ \\
\hline 60 & Rough spherical vesicles & $71 \pm 2.5$ \\
\hline 90 & Agglomerate & $65.5 \pm 2$ \\
\hline
\end{tabular}

Table 4 Characterization of flurbiprofen loaded ethosomes

\begin{tabular}{llllllllll}
\hline Characterization & EF1 & EF2 & EF3 & EF4 & EF5 & EF6 & EF7 & EF8 & EF9 \\
\hline Vesicle Size (d.nm) & $183.0 \pm 3$ & $179.2 \pm 6$ & $177.8 \pm 5$ & $173.8 \pm 6$ & $162.2 \pm 2$ & $191.0 \pm 8$ & $181 . \pm 9$ & $190 . \pm 2$ & $183.5 \pm 1$ \\
\% Entrapment efficiency & $82 \pm 2$ & $85 \pm 1 \%$ & $83.5 \pm 1$ & $87 \pm 1$ & $92.1 \pm 1$ & $86.2 \pm 2$ & $88.2 \pm 2$ & $82.9 \pm 2$ & $90 \pm 1$ \\
PDI & 0.369 & 0.418 & 0.371 & 0.398 & 0.341 & 0.498 & 0.357 & 0.389 & 0.344 \\
Zeta Potential (mV) & $-29.4 \pm 0.5$ & $-43.4 \pm 1.8$ & $-27.3 \pm 2.3$ & $-31 \pm 2.4$ & $-48.14 \pm 1.4$ & $-38.7 \pm 3.1$ & $-34 \pm 0.2$ & $-29.3 \pm 1.3$ & $-35.1 \pm 0.2$ \\
J (flux) ( $\mathrm{fg} / \mathrm{cm} 2 / \mathrm{h})$ & 152.2 & 140.4 & 190.5 & 150.45 & 226.1 & 201.4 & 169.8 & 194.3 & 164.1 \\
pH & 6.6 & 5.4 & 6.1 & 6.3 & 5.2 & 5.4 & 6.4 & 5.1 & 5.1 \\
Viscosity (cps) & $7104 \pm 0.6$ & $6342 \pm 1.4$ & $7534 \pm 2.43$ & $7132 \pm 3.12$ & $8539 \pm 1.1$ & $7432 \pm 1.3$ & $6321 \pm 1.8$ & $7322 \pm 2.1$ & $6076 \pm 1.2$ \\
Spreadability (cm) & $4.1 \pm 3.1$ & $6.84 \pm 0.3$ & $7.22 \pm 2.3$ & $6.4 \pm 0.5$ & $7.12 \pm 0.3$ & $6.43 \pm 0.5$ & $6.54 \pm 3.2$ & $4.3 \pm 3$ & $3.2 \pm 0.3$ \\
\hline
\end{tabular}


exhibited average diameter of $191.0 \pm 8 \mathrm{~nm}$ and confirmed their suitability for drug delivery across skin. In the present study, it was observed that on increasing the ethanol and soya lecithin concentration above $35 \%$ and 200 $\mathrm{mg}$ respectively, particle size was increased drastically and showed narrow distribution for polydispersity index. Therefore either increase or decrease in the ratio of lipid and ethanol widely affect the physical properties of ethosomes. Particle size and ethanol concentration influences the skin permeability as only small sized particles can penetrate through the skin and ethanol concentration remarkably influences drug permeability [22]. Considering the above results it can be concluded that particle size of EF5 was best suited for topical application [23, 24].

The stability of ethosomal formulation was carried out by measuring zeta potential. The zeta potential of different ethosomal formulations from EF1 to EF9 showed value ranging from $-27.3 \pm 2.3 \mathrm{mV}$ to $-48.14 \pm 1.4 \mathrm{mV}$ (Table 4). Formulation EF3 showed minimum $(-27.3 \pm 2.3 \mathrm{mV})$ zeta potential while EF5 showed the maximum $(-48.14 \pm 1.4$ $\mathrm{mV}$ ) value. EF1, EF4 and EF8 exhibited no significant change showing values $-29.4 \pm 0.5,-31 \pm 2.4$ and $-29.3 \pm$ 1.3, respectively. EF2, EF6 and EF9 showed increased zeta potential value i.e. $-43.4 \pm 1.8,-38.7 \pm 3.1$ and $35.1 \pm 0.2$ respectively. Above findings indicated that, the particles in the suspension carried anionic charges and an increase in soya lecithin concentration, further increased anionic charges in the system, and thus resisted agglomeration [17]. Therefore, increase in the surface charge resulted in augmentation of ethosomes stability. From the above results ethosomal formulations EF5, showed maximum stability prepared by thin film hydration method. The results obtained from the zeta potential measurement study, gives us the idea that the charge carried by the vesicles get influenced due to the variation in vesicle sizes.

\section{Morphology of Flurbiprofen loaded ethosomes by TEM, SEM, and AFM}

The external morphology of the prepared optimized formulation EF5 is shown in Fig. 1a. The formulated ethosomes were well acknowledged with their

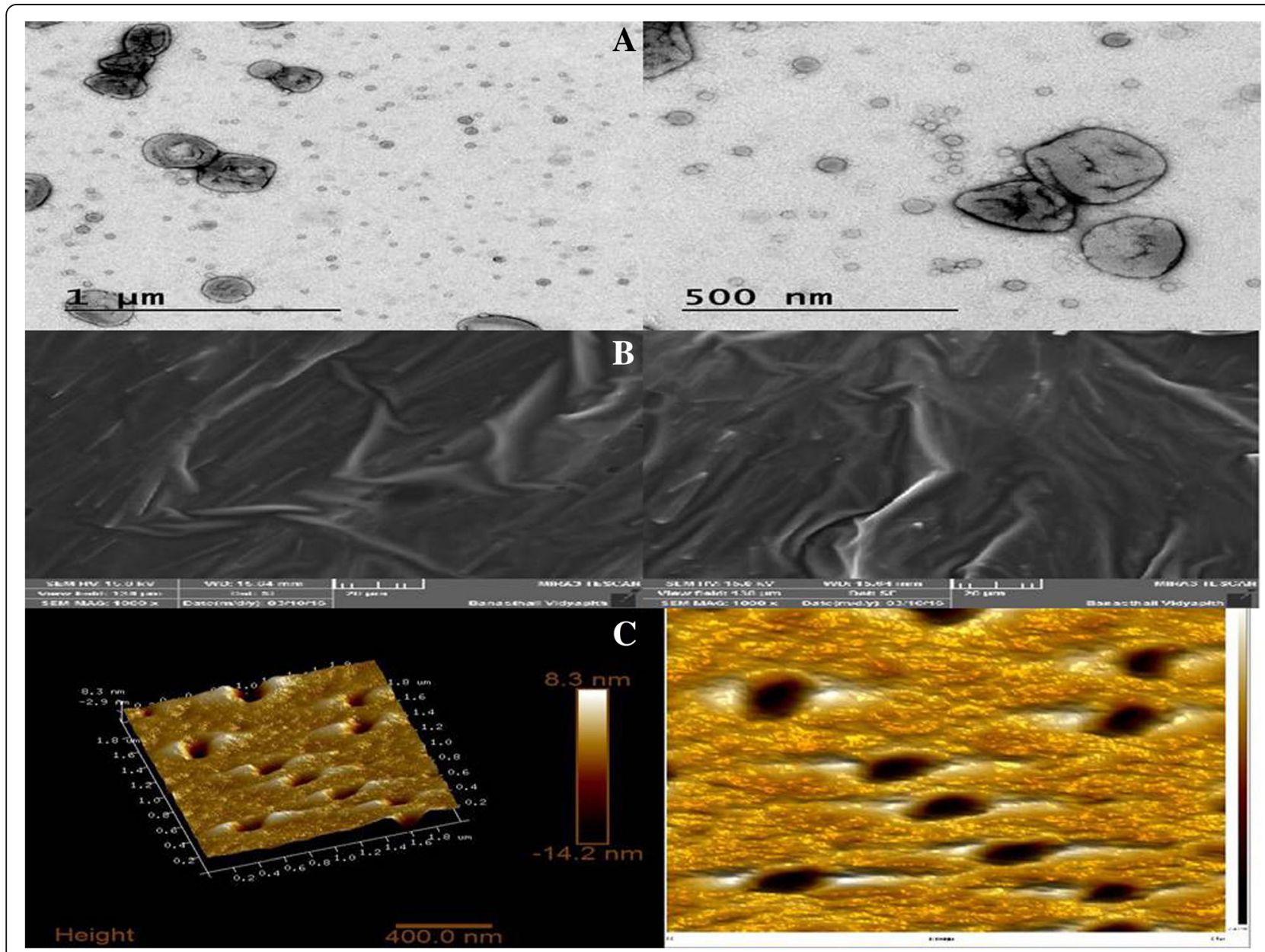

Fig. 1 Surface micrograph of optimized formulation EF 5 shown by [a] TEM [b] SEM [c] AFM 
predominantly spherical texture. The images captured suggested that ethosomes formed were round, smooth, free from drug crystalline structures and multilamellar in nature. The dense particle in the SEM image suggested that lipid was of high density and helped in the controlled release of drug. SEM image of flurbiprofen loaded ethosomal formulation EF5 was shown in Fig. 1b indicated that ethosomes were spherical in shape with clear visible defined boundaries with the nano size range. TEM further helps in confirmation of surface morphology of the optimized formulation, and its finding clearly demonstrated that ethosomes were round, smooth and free from drug crystals.

Further analysis of formulation with AFM images exposed information's regarding behavior of the carriers that cannot be gained so easily by the SEM and TEM images. AFM images of ethosomal formulation were shown in Fig. 1c that provides various facts about the morphological characteristics of prepared ethosomal formulation. Furthermore, the external morphology validated the height and diameter of the molecules. Height of the ethosomes were found as $1.712 \mathrm{~nm}$, area $4138.570 \mathrm{~nm}^{2}$, diameter $59.899 \mathrm{~nm}$ and density $14.597\left(/ \mathrm{mm}^{2}\right)$. These results noticeably predicted that the interaction with the substrate resulted in an even smooth spherical shape since the measured diameter of the average sized structure was $179 \mathrm{~nm}$. No cracks or pinholes were visualized in ethosomes. Ethosomal formulations size were in the range of $162-191 \mathrm{~nm}[25,26]$.

\section{Attenuated total reflection Fourier-transform infra-red spectroscopy}

The ATR-FTIR results of pure drug, soya lecithin and flurbiprofen loaded ethosomal formulation (EF5) was depicted in Fig. 2. ATR-FTIR spectra of the drug showed major characteristic peaks at $3741.09 \mathrm{~cm}^{-1}$ due to $0-\mathrm{H}$ stretching, $2921.58 \mathrm{~cm}^{-1}$ due to $=\mathrm{CH}$ and aromatic $\mathrm{H}$ stretching, and $2852.38 \mathrm{~cm}^{-1}$ due to $\mathrm{CH}_{2}$ stretch, $1731.74 \mathrm{~cm}^{-1}$ due to $\mathrm{C}=\mathrm{O}$ stretching, $1261.16 \mathrm{~cm}^{-1}$ due to $\mathrm{O}-\mathrm{H}$ bending, 1040.62 and $1070.93 \mathrm{~cm}^{-1}$ due to $\mathrm{C}-\mathrm{F}$ bending and $836.36 \mathrm{~cm}^{-1}$ due to distribution of aromatic protons. The above results showed that there was no considerable alteration in the IR peaks of flurbiprofen and optimized formulation specifying the absence of any interactions between the drug and polymer. Further, the above results were also validated by DSC analysis.

\section{Raman spectroscopy}

Raman spectroscopy is dependent on the electric polarizability of the molecule and gives an idea about the functional group present in the sample. The major peak of drug (Flurbiprofen) were shown at $3063 \mathrm{~cm}^{-1}$ (-OH stretching), $3071 \mathrm{~cm}^{-1}$ (aromatic $\mathrm{CH}_{2}$ stretching), $1615 \mathrm{~cm}^{-1}$ (-OH

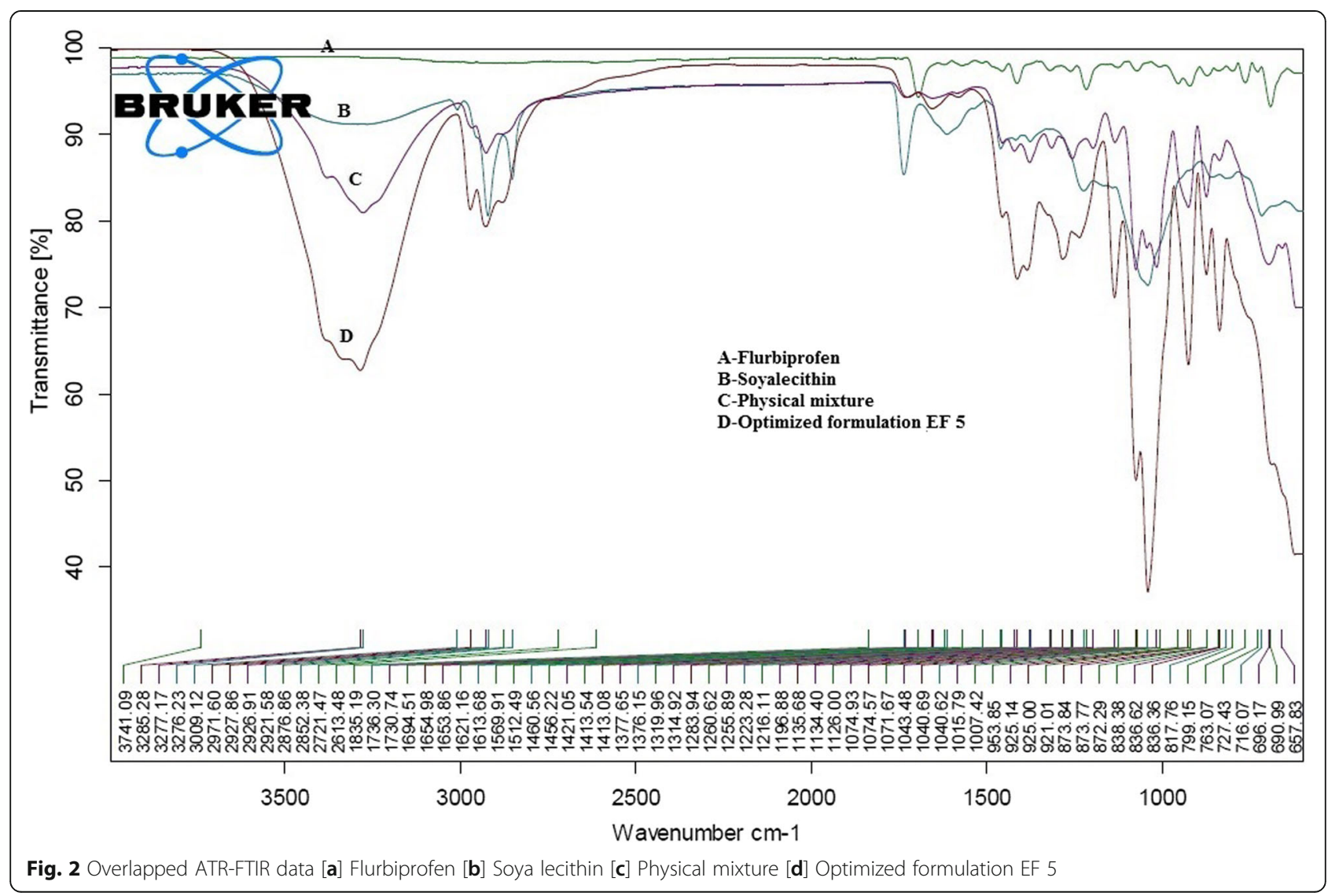




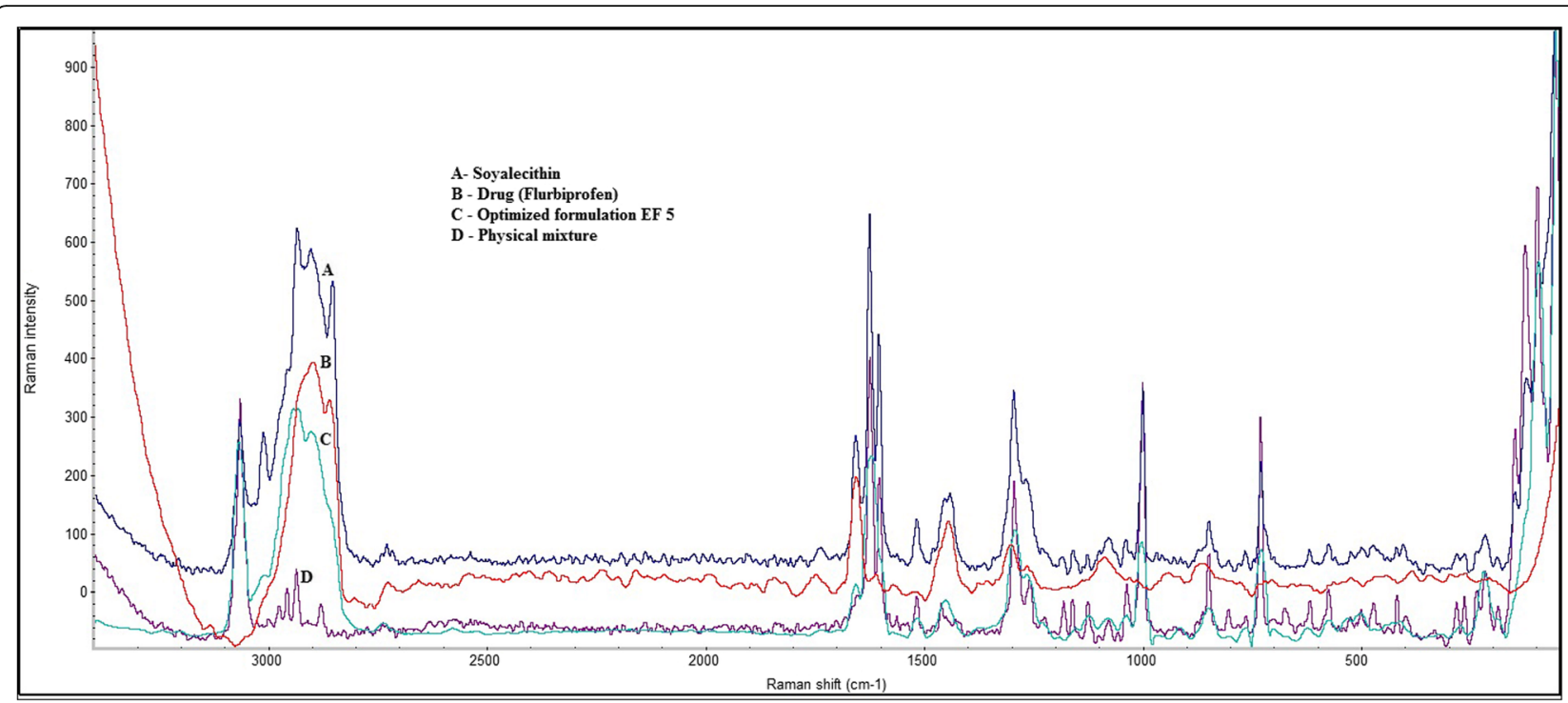

Fig. 3 Overlapped RAMAN spectra [a] Soyalecithin [b] Drug (Flurbiprofen) [c] Optimized formulation EF 5 [d] Physical mixture

bending), $1300 \mathrm{~cm}^{-1}$ ( $\mathrm{CH}_{3}$ bending), $1033 \mathrm{~cm}^{-1}$ (C-F) while formulation EF-5 showed peak at $3010 \mathrm{~cm}^{-1}, 2904 \mathrm{~cm}^{-1}$, $2856 \mathrm{~cm}^{-1}, 1658 \mathrm{~cm}^{-1}, 1445 \mathrm{~cm}^{-1}, 1303 \mathrm{~cm}^{-1}, 1003 \mathrm{~cm}^{-1}$, $1089 \mathrm{~cm}^{-}{ }^{1}$. The soyalecithin peaks were showed at 2853 $\mathrm{cm}^{-1}, 2193 \mathrm{~cm}^{-1}, 2030 \mathrm{~cm}^{-1}, 1825 \mathrm{~cm}^{-1}, 1730 \mathrm{~cm}^{-1}, 1653$ $\mathrm{cm}^{-1}, 1300 \mathrm{~cm}^{-1}$ and physical mixture showed peaks at $2857 \mathrm{~cm}^{-1}, 2726 \mathrm{~cm}^{-1}, 1732 \mathrm{~cm}^{-1}, 1442 \mathrm{~cm}^{-1}, 1299 \mathrm{~cm}^{-1}$, $1076 \mathrm{~cm}^{-1}$. All the components present in the formulation along with its physical mixture were scanned and it was observed that there were least interaction between the different samples and peak of optimized formulation were overlapping with drug which show the presence of drug in ethosomal formulation. Data was matched with the FTIR for the presence of different functional group. Overlapping peaks was represented in Fig. 3.

\section{DSC analysis}

With the help of DSC instrument, thermal behavior and various interactions between drug (flurbiprofen), lipid (Soya lecithin) and physical mixture were studied. Results of DSC experiments showing endothermic peaks of drug, drug loaded ethosomes and physical mixtures (drug + lecithin) were depicted in Fig. 4. The DSC thermogram of flurbiprofen exhibited a sharp and high

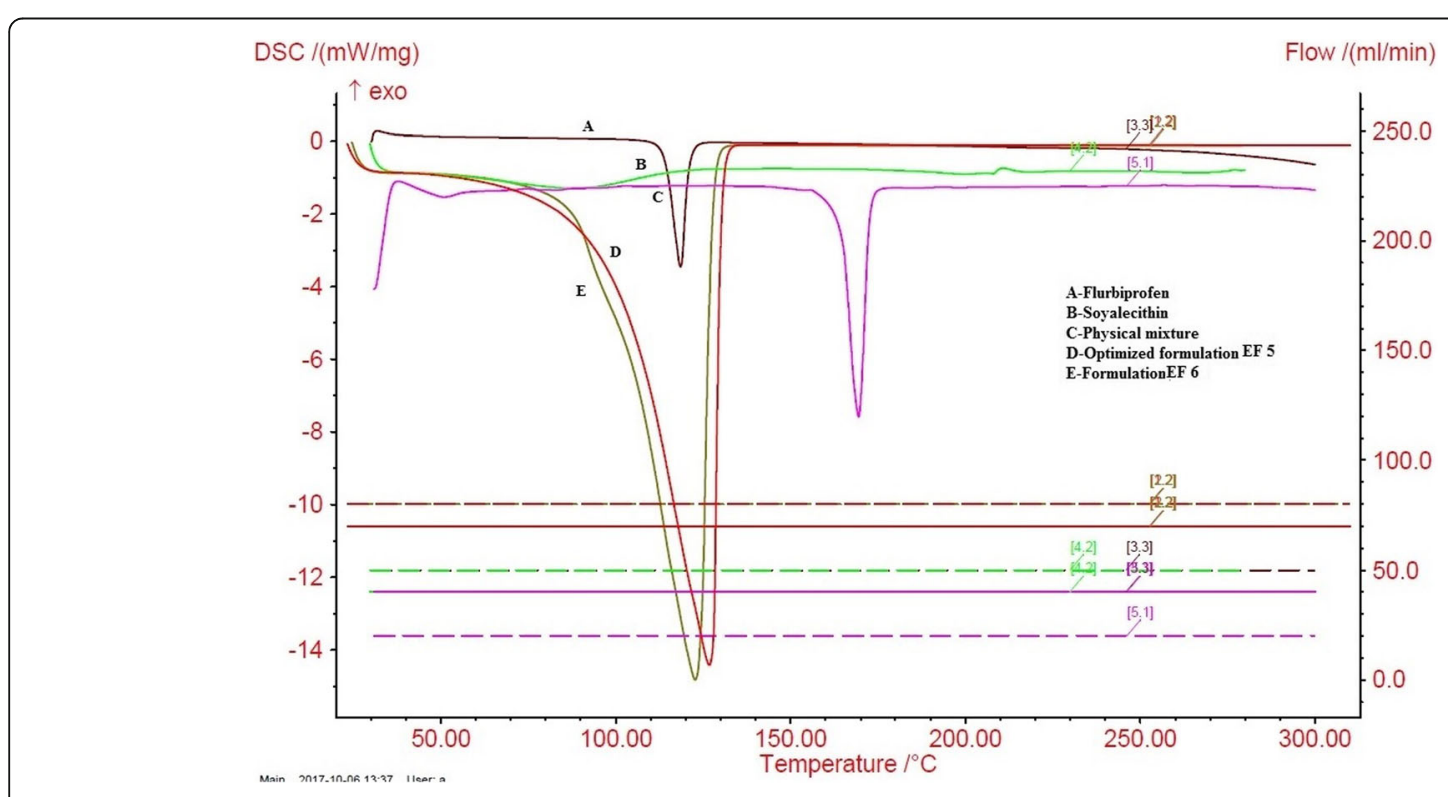

Fig. 4 Overlapped DSC Thermogram [a] Flurbiprofen [b] Soya lecithin [c] Physical formulation [d] Optimized Formulation ES 5 [e] Formulation EF 6 
intensity peak at $117^{\circ} \mathrm{C}$. Broad endothermic and low intensity soya lecithin peak was found at $87^{\circ} \mathrm{C}$. The melting point for optimized formulation EF5 showed sharp and high endothermic peak at $121^{\circ} \mathrm{C}$ which was found very close to our standard drug flurbiprofen. The peak of formulation EF1was found at $129^{\circ} \mathrm{C}$. The melting point for optimized formulation showed peak of high intensity compared to the pure drug. On increasing ethanol concentration from 30 to $35 \%$ the phase transition temperature decreases. With the addition of ethanol up to $40 \%$, the phase transition behaviour disappeared. However the transition enthalpy and entropy get increased with the increase in ethanol concentration [27]. This implies that our optimized formulation EF5 shows no interaction with other excipients. DSC helps in critical evaluation of the effectiveness and absolute purity determination of drugs. The result shows good compromise between accuracy, resolution and sensitivity.

\section{Thermo gravimetric analysis (TGA)}

In the present study, TGA was performed to measure the change in mass of the sample with respect to temperature change. The experiment involves the study of flurbiprofen, soya lecithin, physical mixture and optimized formulation (EF5) in order to examine their thermal property. The \% weight loss and the melting temperature for the samples are depicted in Figure as A) Flurbiprofen B) Physical mixture C) Soya lecithin and D) Optimized formulation EF5. The TGA weight loss \% for flurbiprofen, Soya lecithin and physical mixture was found to be 97,94 and $92 \%$ at 200 to $250^{\circ} \mathrm{C}, 250$ to $300^{\circ} \mathrm{C}$ and 250 to $275^{\circ} \mathrm{C}$ respectively. Optimized formulation EF5 showed instant $88 \%$ weight loss at 100 to $120^{\circ} \mathrm{C}$ and became constant till $300^{\circ} \mathrm{C}$. From the above TGA result, it is clearly indicated that the mixture of soya lecithin with the drug improves its stability. TGA shows a useful means for evaluating the weight loss of the polymers and drug. All these outcomes discovered that excipients or moisture content have no

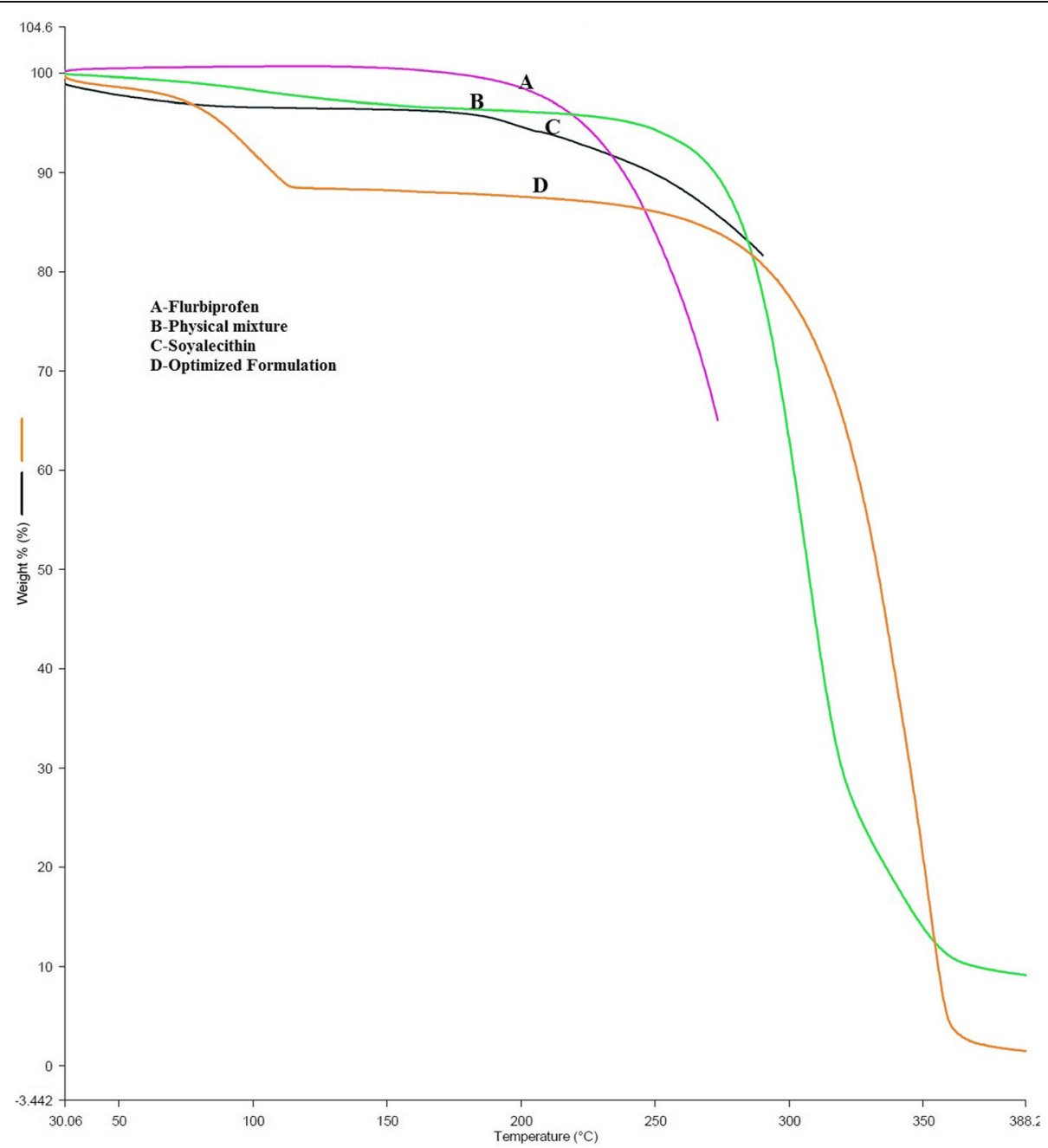

Fig. 5 Overlapped TGA thermograph: [a] Flurbiprofen [b] Physical Mixture [c] Soya lecithin [d] Optimized formulation EF 5 


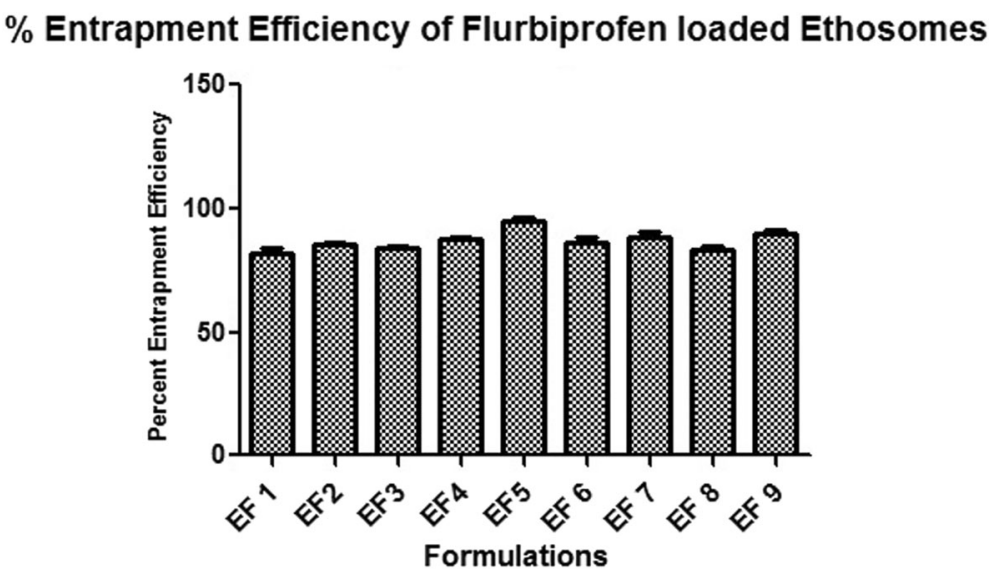

Fig. 6 Percent entrapment efficiency of formulation EF 1-EF 9

or minimal opposing effects on the formulations. Overlapped TGA spectra was shown in Fig. 5.

\section{Entrapment efficiency of ethosomes}

Entrapment efficiency is an important parameter that assesses the delivery potentiality of a system. The entrapment efficiency of all formulations with different concentration of flurbiprofen loaded ethosomes were determined and summarized in Table 4. In the midst of all the formulations, EF5 was found to have maximum $92.1 \pm 0.1 \%$ and EF1 showed the minimum $82 \pm 2 \%$ encapsulation efficiency. Maximum entrapment efficiency of optimized formulation EF5 was contributed due to the presence of average amount of lipid and ethanol i.e. $200 \mathrm{mg}$ 35\% respectively. Formulation EF1, EF2, EF4 and EF6 showed no significant difference in entrapment efficiency showing values $82 \pm 2 \%, 85 \pm 1 \%, 87 \pm 1 \%$ and $86.2 \pm 2 \%$ respectively. However, decreased value of entrapment efficiency was observed in EF3, EF8 and EF9 compared to rest formulations $[17,28]$. The entrapment efficiency was increased on increasing alcohol content up to $35 \%$, however efficiency decreased when the ethanol concentration was increased above $35 \%$. This could be due to the higher permeation enhancing property of ethanol that leads to the leakage of lipid bilayer. Also, the entrapment efficiency increases with increase in concentration of lecithin up to $200 \mathrm{mg}$ but, above $200 \mathrm{mg}$ of lecithin concentration drug permeability was reduced. However, it was also observed that formulation EF6 containing same amount of lipid i.e. $200 \mathrm{mg}$ showed less entrapment efficiency, this could be due to the increased ethanol concentration i.e. $40 \%$ in the formulation. Also, it is commonly known that high concentration of ethanol cannot co-exist with lipid vesicles. From the above results, it can be concluded that particle size and entrapment efficiency of ethosomes formulation could be significantly

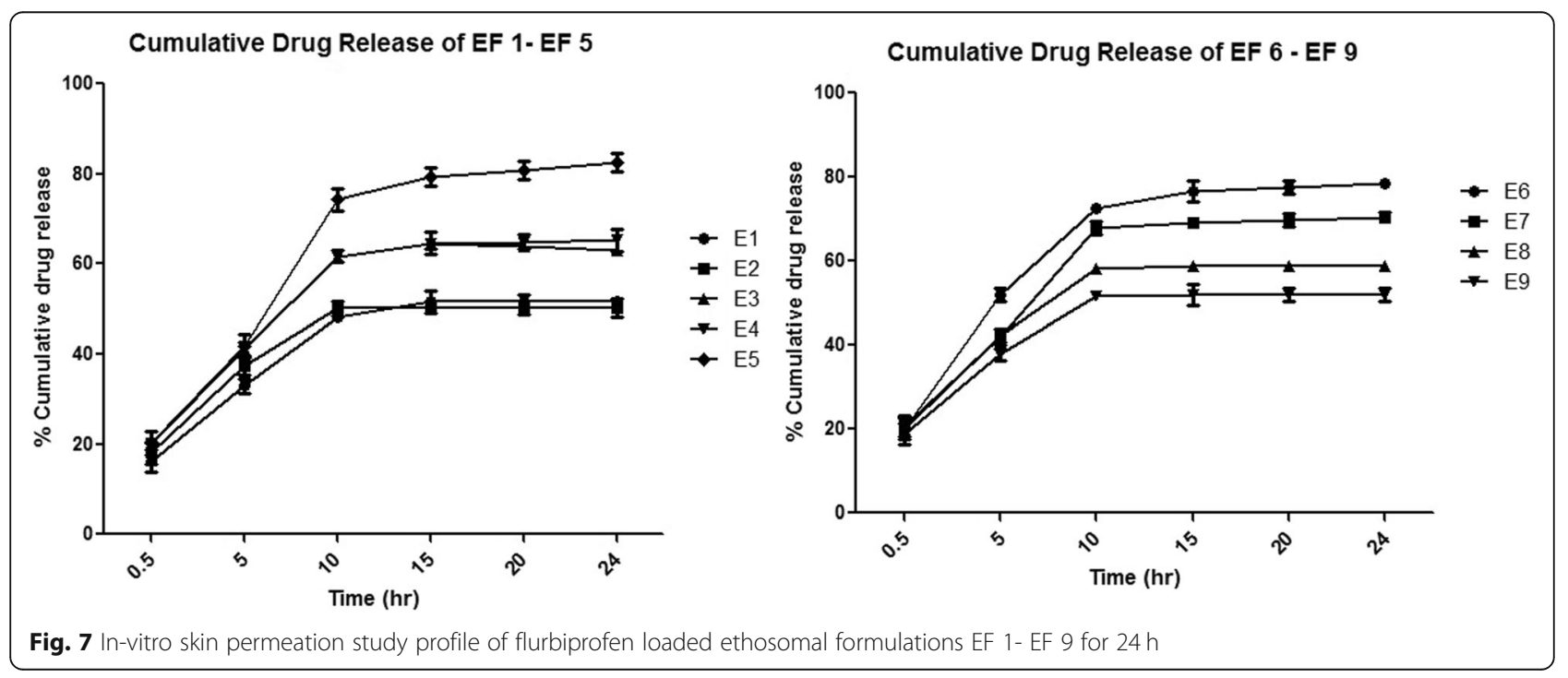




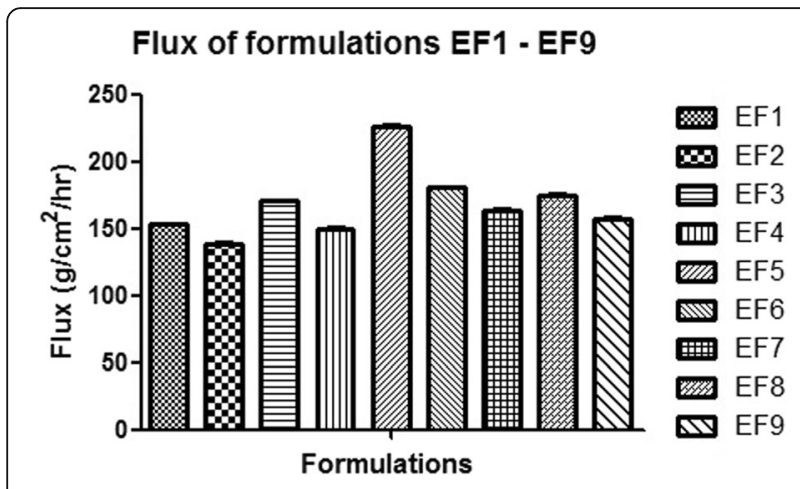

Fig. 8 Flux of the formulation EF 1- EF 9

affected by varying the ethanol and lipid concentration and by keeping other variables constant [29]. The order for entrapment efficiency was found to be EF5 $>$ EF9 $>$ $\mathrm{EF} 7>\mathrm{EF} 4>\mathrm{EF} 6>\mathrm{EF} 2>\mathrm{EF} 3>\mathrm{EF} 8>\mathrm{EF} 1$ and it was graphically shown in Fig. 6.

\section{Viscosity, $\mathrm{pH}$ and Spreadability}

The viscosity, $\mathrm{pH}$ and spreadability of the gel were found to be $6076 \pm 1.2$ to $7534 \pm 1.2,5.1$ to 6.6 and $32 \pm 0.3$ to $7.22 \pm 0.3 \mathrm{~cm}$ respectively which are suitable for the application over skin and the results were shown in Table 4 . Above optimized formulation EF5 displayed sufficient viscosity, $\mathrm{pH}$ and spreadability which revealed a good gelling property of ethosomal gel for topical application. Results of the study revealed that, ethanol and lipid concentration for formulation EF5 was found to be optimized considering the all parameters mentioned in Table $4[28,30]$. Further ethosomal suspension was incorporated into $1 \%$ Carbopol gel for topical application. Ethosomal formulation of apigenin having anti-inflammatory, anti-oxidant and anti-carcinogenic properties showed enhanced skin deposition and transdermal flux with increase in the level of phospholipid and ethanol concentration [31]. High ethanol concentration plays major role in the formulation of ethosomes [32].

\section{Skin irritation assay in rat}

The skin irritation assay was performed by applying free drug and optimized formulation EF5 on rat skin and observed for $72 \mathrm{~h}$. The moderate to severe erythema was observed in terms of Primary irritation index (PII) for both the test compounds i.e. drug and EF5. For free flurbiprofen solution PII was found as 1.6 which restricts the suitability and tolerability by the recipients. In contrary, EF5 formulation caused less irritation with PII of 1.0. Flurbiprofen is commensally associated with rashes and rarely with encrusted skin. So it cannot be used directly by the patients. Flurbiprofen loaded ethosomes should be able to reduce the irritation due to the increased encapsulation efficiency of the drug. Therefore, EF5 can be reliably used in dermal issues and can be considered safe for topical formulation. Flurbiprofen is associated with noticeable skin problems like skin rashes, which strongly restricts their applicability and acceptability by the patients. Ideally, the flurbiprofen containing ethosomes could be able to reduce irritation and improves patient acceptability.

\section{In vitro skin permeation study}

The In vitro skin permeation studies for various formulations were studied using Albino rat skin. The change in ethanol and lipid concentrations plays an important role in the release of flurbiprofen from ethosomal formulation. The results of transdermal skin permeation of different formulations from EF1 to EF9 were shown in Fig. 7. The drug permeation study through rat skin was examined for $24 \mathrm{~h}$ and the formulations EF1 to EF9 showed cumulative results as $51.59 \pm 1.12,50.12 \pm$ $2.01, \quad 63.16 \pm 1.01, \quad 63.23 \pm 2.52, \quad 82.56 \pm 2.11, \quad 78.52 \pm$ $1.21,70.25 \pm 1.21,58.75 \pm 1.01$ and $51.85 \pm 1.52 \mathrm{~g} / \mathrm{cm}^{2}$
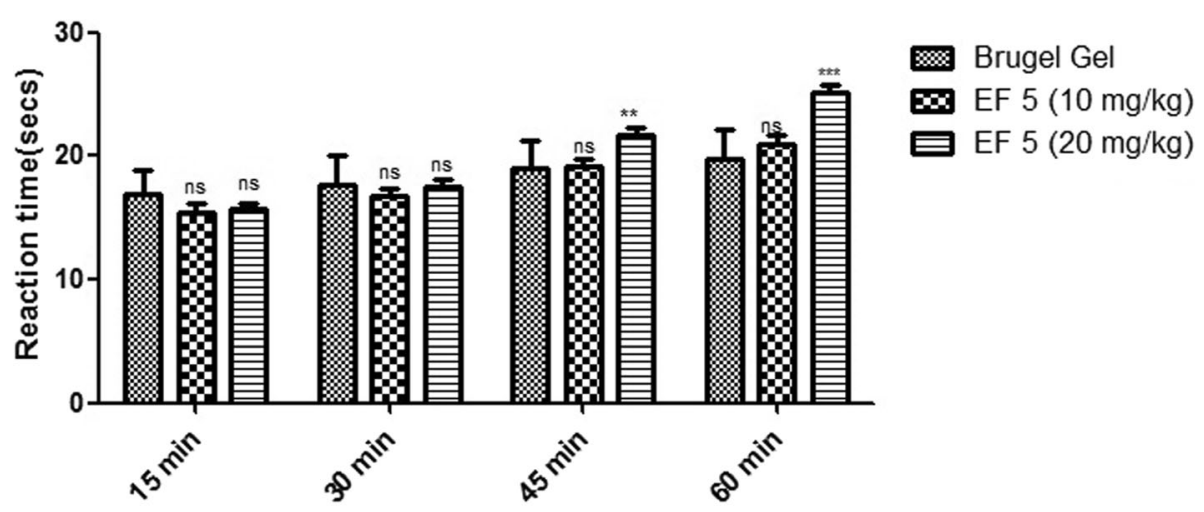

Treatment

Fig. 9 Effect of EF 5 formulations on reaction time in cold plate test 
Table 5 Screening of analgesic activity of selected formulations using cold plate test in rats

\begin{tabular}{|c|c|c|c|c|c|}
\hline \multirow[t]{2}{*}{ S.No. } & \multirow[t]{2}{*}{ Treatment } & \multicolumn{4}{|c|}{ Reaction time (sec.) } \\
\hline & & $15 \mathrm{~min}$ & $30 \mathrm{~min}$ & $45 \mathrm{~min}$ & $60 \mathrm{~min}$ \\
\hline I & Brugel Gel & $16.9 \pm 2.02$ & $17.7 \pm 2.4$ & $19 \pm 2.21$ & $19.8 \pm 2.41$ \\
\hline$\|$ & Etho $5(10 \mathrm{mg} / \mathrm{kg})$ & $15.33 \pm 0.51^{\mathrm{ns}}$ & $16.8 \pm 0.63^{\mathrm{ns}}$ & $19.2 \pm 0.63^{\mathrm{ns}}$ & $21 \pm 0.63^{\mathrm{ns}}$ \\
\hline III & Etho $5(20 \mathrm{mg} / \mathrm{kg})$ & $15.66 \pm 0.81^{\mathrm{ns}}$ & $17.48 \pm 0.5^{\mathrm{ns}}$ & $21.66 \pm 0.51^{* *}$ & $25.16 \pm 0.40^{*}$ \\
\hline
\end{tabular}

ns Not significant

**Significant

***Highly significant

respectively. From the above results it was clear that EF5 showed maximum release i.e. $82.56 \pm 2.11 \mathrm{~g} / \mathrm{cm}^{2}$, possibly due to the greater entrapment of drug in ethosomes in comparison to other formulations. Initially ethosomes shows burst release of drug and then sustained release thereafter. The sustained release is accredited to the presence of lipid bilayer composed of lipid that acts as a rate limiting membrane for release of the encapsulated drug [32]. A rapid release was obtained for EF1 and EF2 formulations which had low lipid concentration. Also, there was no significant difference in drug permeation for the formulation EF7, EF8 and EF9 prepared with the high concentration of lipid $300 \mathrm{mg}$ and varied concentration of ethanol. EF2 showed minimum amount of drug permeation $50.12 \pm 2.01 \mathrm{~g} / \mathrm{cm}^{2}$ due to less encapsulation efficiency. The obtained optimized formulation EF5 followed Korsmeyer-peppas release pattern and anomalous (non-Fickian) transport behavior. From the above results it can be predicted that variation in lipid and ethanol concentrations may modify the drug release patterns in all formulations [23].

\section{Data treatment result}

The data obtained from in vitro skin permeation study were further treated mathematically to obtain the value of flux for all formulations. The flux value for all formulations from EF1 to EF9 lies between 140.4 to $226.1 \mu \mathrm{g} / \mathrm{cm}^{2} / \mathrm{h}$. Optimized formulation EF5 showed maximum flux value $226.1 \mu \mathrm{g} / \mathrm{cm}^{2} / \mathrm{h}$. The results were tabulated in Table 4 as well as depicted in Fig. 8. Flurbiprofen loaded ethosomes provided better flux as compared to the other reported formulations and also provided a greater skin deposition, thus qualifying its use as a carrier for choice in dermal and transdermal delivery. Ethosomal formulation has been reported as non-irritant and well tolerated in vivo [33, 34]. Differences in the flux values were indicative of varying concentration of lipid: ethanol ratio in formulations.

\section{Cold plate test}

The formulations showed dose dependent increase in the reaction time for 10 and $20 \mathrm{mg} / \mathrm{kg}$ as similar to Brugel ${ }^{\circ}$ marketed preparation markedly (Table 5, Fig. 9). EF 5 formulations at dose of $10 \mathrm{mg} / \mathrm{kg}$ (from $15.33 \pm 0.51$ to $21 \pm$ $0.63 \mathrm{~min})$ and $20 \mathrm{mg} / \mathrm{kg}(15.66 \pm 0.81$ to $25.16 \pm 0.40 \mathrm{~min})$ caused remarkable increase in reaction time (Additional file 1). The cold plate test has been considered as an ideal test for evaluation of centrally acting therapeutic agents. Formulations EF 5 showed marked analgesic activity, which could be due to involvement of opioid receptors. The opioid agents exert their analgesic action via the supraspinal $(\mu 1, \mathrm{k} 3, \delta 1, \sigma 2)$ and spinal $(\mu 2, \mathrm{k} 1, \delta 2)$ receptors. From our result, it can be concluded that it is possible that our formulations exert its effect through the central opioid receptor or promoted release of endogenous opioid peptides [35]. R-flurbiprofen demonstrates potent analgesic activity via inhibition of $\mathrm{COX}$ and possess minimal toxicities.

\section{Carrageenan induced paw edema}

As shown in Table 6, Fig. 10, EF 5 formulation at $10 \mathrm{mg} /$ $\mathrm{kg}$ inhibited the increase in paw edema $(2.83 \pm 0.04$ to $2.41 \pm 0.05 \mathrm{~min}$ ) from $15 \mathrm{~min}$ to $90 \mathrm{~min}$. Similarly, EF 5 at $20 \mathrm{mg} / \mathrm{kg}$ significantly inhibited paw edema $(2.82 \pm$ 0.06 to $2.35 \pm 0.05$ ) from $15 \mathrm{~min}$ to $90 \mathrm{~min}$ as compared to Brugel $^{\circ}$ marketed preparation. A dose dependent

Table 6 Screening of anti-inflammatory activity of selected formulation in carrageenan induced paw edema in rats

\begin{tabular}{|c|c|c|c|c|c|c|c|}
\hline \multirow[t]{2}{*}{ S.No. } & \multirow[t]{2}{*}{ Treatment } & \multicolumn{6}{|c|}{ Swelling index (cm) } \\
\hline & & $15 \mathrm{~min}$ & $30 \mathrm{~min}$ & $45 \min$ & $60 \min$ & $75 \mathrm{~min}$ & $90 \mathrm{~min}$ \\
\hline I & Brugel Gel & $2.81 \pm 0.04$ & $2.76 \pm 0.05$ & $2.68 \pm 0.04$ & $2.63 \pm 0.05$ & $2.59 \pm 0.06$ & $2.55 \pm 0.05$ \\
\hline$\|$ & Etho5 $(10 \mathrm{mg} / \mathrm{kg})$ & $2.83 \pm 0.05^{\mathrm{ns}}$ & $2.7 \pm 0.06^{\mathrm{ns}}$ & $2.66 \pm 0.05^{\text {ns }}$ & $2.53 \pm 0.05^{* * *}$ & $2.45 \pm 0.05^{* * *}$ & $2.41 \pm 0.04^{* * *}$ \\
\hline III & Etho5 $(20 \mathrm{mg} / \mathrm{kg})$ & $2.82 \pm 0.06^{\mathrm{ns}}$ & $2.67 \pm 0.05^{* * *}$ & $2.62 \pm 0.06^{\mathrm{ns}}$ & $2.55 \pm 0.05^{\mathrm{ns}}$ & $2.45 \pm 0.05^{* * *}$ & $2.35 \pm 0.05^{* * *}$ \\
\hline
\end{tabular}




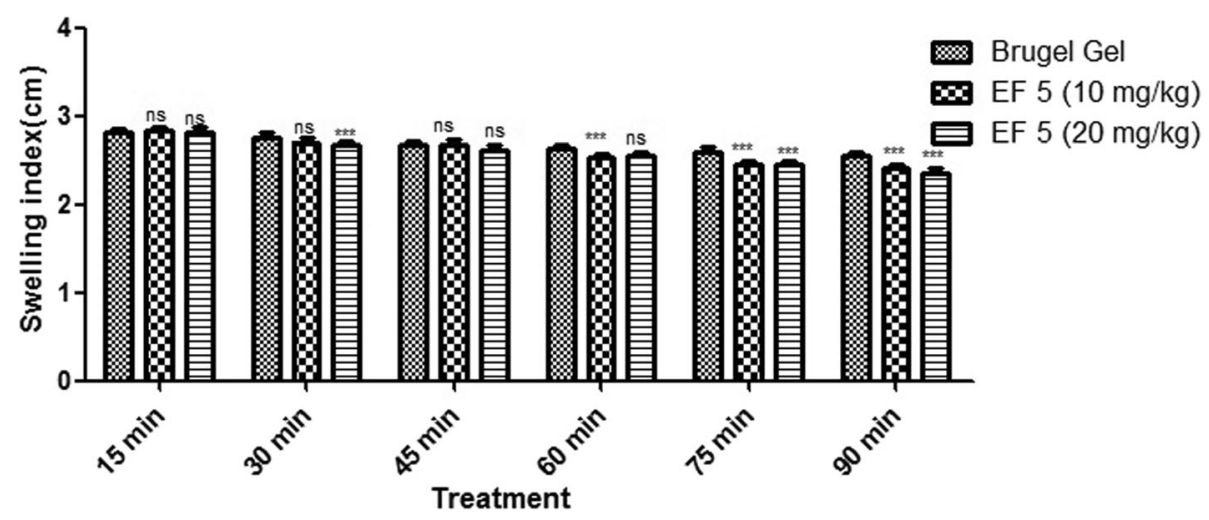

Fig. 10 Effect of formulations on swelling index in carrageenan induced inflammation

inhibition in paw edema was observed for both the formulations at 10 and $20 \mathrm{mg} / \mathrm{kg}$. Carrageenan induced paw edema is a widely used model to assess anti-inflammatory capacity of any compound. A biphasic response is usually achieved after parentarally administered carrageenan, i. e. first phase of 15-45 min includes release of mediators like bradykinin, serotonin and histamine while second phase of 60-90 min implicates release of prostaglandins only. Carrageenan-induced rat paw edema model was used to investigate anti-inflammatory activity of flurbiprofen proniosomes [36]. In vivo interaction studies of ACE inhibitor (Lisinopril) with commonly used NSAIDs flurbiprofen and ibuprofen in carrageenan induced inflammation (CII) rats to check the anti-inflammatory response of NSAIDs with Lisinopril and alone [37].

\section{Conclusion}

The development of a suitable carrier for dermal administration of flurbiprofen has been highly challenging due to its hydrophilic nature, resulting in limited liberation into the skin. The formation of more lipophilic carrier for flurbiprofen for adequate solublization capacity and enhanced penetrative properties would be expected to increase the bioavailability of the drug. Ethosomes appears to be the suitable carrier for flurbiprofen for dermal delivery by entrapping the drug in between the lipophilic layer. Several reports have advocated that an ethosomal formulation provides consistent skin permeability and enhanced drug permeation from lipid vesicles having ethanol as one of key components. Therefore the goal of present study was to develop ethosomal delivery of flurbiprofen. Notably, our current investigation revealed that flurbiprofen loaded ethosomes as potentially useful vehicle. They have provided ideal particle size, PDI, enhanced transdermal flux, higher encapsulation efficiency with lower skin irritancy and higher stability at $4{ }^{\circ} \mathrm{C} / 60 \pm 5 \mathrm{RH}$. Delivery of drug by ethosomes was significantly influenced by variations in lipid and ethanol concentrations in formulations. Thus, the overall study concluded that this ethosomal approach offers a new delivery system for sustained and targeted delivery for flurbiprofen. Based on this approach, future research works is needed to bring the flurbiprofen loaded ethosomal formulation closer to its clinical realization.

\section{Additional file}

Additional file 1: Raw data for anti-inflammatory actvity is available in additional file. Raw observations for preclinical study is available in supplementary file. (DOC $1135 \mathrm{~kb}$ )

\begin{abstract}
Abbreviations
\%: Percentage; API: Active pharmaceutical ingredient; CDR: Cumulative drug release; $\mathrm{cm}$ : Centimeters; DSC: Differential scanning calorimetry; FDA: Food and Drugs Administration; FTIR: Fourier transformed infra red; g/L: Gram per litre; gm/ml: Gram per millilitre; h: Hour; ICH: International Conference on Harmonization; J: Flux; NSAID: Non-steroidal anti-inflammatory drug; PDI: poly dispersive index; PL: Phospholipids; rpm: Rotations per minute; SC: Stratum corneum; SEM: Scanning electron microscopy;

TDDS: Transdermal drug delivery system; TEA: Triethyl amine; UV: Ultra violet; $\mu$ : Microns
\end{abstract}

\section{Acknowledgements}

Authors would like to express their gratitude to Department of Physics and Department of Chemistry of Banasthali Vidyapith, Banasthali, Rajasthan, India for extended instrumental facility in successful accomplishment of the present work.

\section{Competing of interest}

The authors report no conflict of interest.

\section{Funding}

The work was waived by editorial office of jourenal Lipids in Health and Disease.

\section{Availability of data and materials}

Corresponding author can be approach for that.

\section{Authors' contribution}

Sarvesh Paliwal and Vivek Dave has designed entire study. Amita Tilak, Renubala Yadav and Jaiprakash Sharma have developed and characterized the formulations, Saraswati Patel and Kanika Verma performed in vitro and in vivo antihypertensive activity in rats. Swapnil Sharma has supervised 
pharmacological studies. Kajal Tak drafted the manuscript which was further checked by Vivek Dave.

\section{Ethics approval and consent to participate}

Animal experimental protocols were approved by Institutional Animal Ethical Committee (Ref. no. BU/3431/16-17)

\section{Consent for publication}

No such data incorporated.

\section{Publisher's Note}

Springer Nature remains neutral with regard to jurisdictional claims in published maps and institutional affiliations.

\section{Author details}

'Department of Pharmacy, Banasthali Vidyapith, Banasthali, Rajasthan 304022, India. ${ }^{2}$ Department of Pharmacy, SMS Medical College, Banasthali, Rajasthan, India.

Received: 3 January 2019 Accepted: 6 May 2019

Published online: 07 June 2019

\section{References}

1. Bragagni M, Mennini N, Maestrelli F, Cirri M, Mura P. Comparative study of liposomes, transfersomes and ethosomes as carriers for improving topical delivery of celecoxib. J Drug Deliv. 2012;19:354-61.

2. Sercombe L, Veerati T, Moheimani F, Wu SY, Sood AK, Hua S. Advances and challenges of liposomes assisted drug delivery. Front Pharmacol. 2015;6:286-99.

3. Mokhtar M, Sammour AO, Mohammed AH, Nagia EM. Effect of some formulation parameters on flurbiprofen encapsulation and release rates of niosomes prepared from proniosomes. Int J Pharm. 2008;361:104-11.

4. Zongling QIN, Yi Y. Preparation and quality control of Flurbiprofen Ethosomal gel. J Pharm Pract. 2007;1:1-4.

5. Vijayakumar KS, Parthiban S, Senthilkumar GP. Vikneswari a effect of soyalecithin concentration on formulation of ethosomes. Int J Res Pharm Nano Sciences. 2014;3:450-60.

6. Dave V, Sharma S, Yadav RB, Agarwal U. Herbal liposome for the topical delivery of ketoconazole for the effective treatment of seborrheic dermatitis. Appl Nanosci. 2017;(8):973-87.

7. Dave V, Yadav RB, Kushwaha K. Hybrid nanoparticles for the topical delivery of Norfloxacin for the effective treatment of bacterial infection produced after burn. J Microencapsul. 2017;21:351-65.

8. Sharma P, Pant S, Rai S, Yadav RB, Dave V. Green synthesis of silver nanoparticle capped with Allium cepa and their catalytic reduction of textile dyes: an ecofriendly approach. J Polym Environ. 2017;26:1795-803.

9. Yub HN, Afzal MT, Azizan MT. TGA analysis of rubber seed kernel Int J Eng. (20133):639-52.

10. Babu R, Kanikkannan N, Kikwai L, Ortega C, Andega S, Ball K, Yim S, Singh M. The influence of various methods of cold storage of skin on the permeation of melatonin and nimesulide. J Control Release. 2013;86:49-57.

11. Ling G, Zhang P, Zhang W, Sun J, Meng Z, Qin Y, Deng Y, He Z. Development of novel self-assembled DS-PLGA hybrid nanoparticles for improving oral bioavailability of vincristine sulphate by P-gp inhibition. J Control Release. 2010;148:241-8.

12. Shah PP, Desai PR, Singh M. Effect of oleic acid modified polymeric bilayered nanoparticles on percutaneous delivery of spantide II and ketoprofen. J Control Release. 2012;158:336-45.

13. Panigrahi L, Ghosal SK, Pattnaik S, Maharana L, Barik BB. Effect of permeation enhancers on the release and permeation kinetics of lincomycin hydrochloride gel formulations through mouse skin. Indian J Pharm Sci. 2006;68:205-11.

14. Liua Y, Pana J, Fenga S. Nanoparticles of lipid monolayer shell and biodegradable polymer core for controlled release of paclitaxel: effects of surfactants on particles size, characteristics and in vitro performance. Int J Pharm. 2010;16:243-50.

15. Jaybhaye D, Varma S, Gagne N, Bonde V, Gite A, Bhosle D. Effect of tectona grandis Linn. Seeds on hair growth activity of albino mice. Int J Ayurveda Res. 2010;4:1-12.

16. Harer SL, Rajurkar VG, Patil P, Harer PS, Navale SD, Awuti ST, Synthesis SAA Characterization and anti-microbial evaluation of some 2-lodo- $N^{\prime}-[(1 E)$ - substituted phenylmethylidene] benzohydrazide analogues. Int J Pharm Sci Drug Res. 2012;2:134-6.

17. Agrawal U, Mehra NK, Gupta U, Jain NK. Hyper branched dendritic nano-carriers for topical delivery of dithranol. J Drug Target. 2013;21:497-506.

18. Shokri J, Nokhodchi A, Dashbolaghi A, Hassan-Zadeh D, Ghafourian T, Barzegar MJ. The effect of surfactants on the skin penetration of diazepam. Int J Pharm. 2001;228:99-107.

19. Kasture SB. "A handbook of experiments in pre-clinical pharmacology", career publications; 2009.

20. Verma DD, Verma S, Blume G, Fahr A. Particle size of liposomes influences dermal delivery of substances into skin. Int J Pharm. 2003;258:141-51.

21. Plessis JD, Ramachandran C, Weiner N, Müller DG. The influence of particle size of liposomes on the deposition of drug into skin. Int J Pharm. 1994:103:277-82.

22. Limsuwana T, Amnuaikita T. Development of ethosomes containing mycophenolic acid. Procedia Chem. 2012;4:328-35.

23. Cheow W, Hadinoto K. Lipid-polymer hybrid nanoparticles with rhamnolipid triggered release capabilities as anti-biofilm drug delivery vehicle. Particuology. 2010;10:327-33.

24. Liu Y, Pan J, Feng S. Nanoparticles of lipid monolayer shell and biodegradable polymer core for controlled release of paclitaxel: effects of surfactants on particles size, characteristics and in vitro performance. Int J Pharm. 2010;395:243-50.

25. Bratu I, Borodi G, Kacso I, Moldovana Z, Filip C, Dragan F, Vasilescu M, Simon S. New solid form of Norfloxacin: structural studies. J Spectro. 2011;25:53-62.

26. Muller RH, Radtke M, Wissing SA. Solid lipid nanoparticles and nanostructured lipid carriers in cosmetics and dermatological preparations Adv. Drug Deliv Rev. 2002;54:131-55.

27. Zeng J, Chong PLG. Effect of ethanol-induced lipid Interdigitation on the membrane solubility of Prodan, Acdan, and Laurdan. Biophys J. 1995;68:567-73.

28. Mandal B, Bhattacharjee H, Mittal SH, Balabathula P, Thoma LA, Wood GC. Core-shell type lipid-polymer hybrid nanoparticles as a drug delivery platform. Nanomed: Nanotechnol Biol Med. 2013;9:474-91.

29. Dave $V$, Kumar D, Lewis S, Paliwal S. Ethosome for enhanced transdermal drug delivery of Aceclofenac. Int J Drug Deliv. 2010;2:81-92.

30. Zhou L, Yuan J, Yuan W, Sui X, Wu S, Li Z, Shen D. Synthesis, characterization, and controllable drug release of $\mathrm{pH}$-sensitive hybrid nanoparticles. J Magne Magn Mater. 2009;321:2799-804.

31. Shen $L N$, Zhang $Y T$, Wang $Q, X u L$, Feng NP. Enhanced in vitro and in vivo skin deposition of apigenin delivered using ethosomes. Int J Pharm. 2014:460:280-8.

32. Touitou E, Dayana N, Bergelsonb L, Godina B, Eliaza M. Ethosomes - novel vesicular carriers for enhanced delivery: characterization and skin penetration properties. J Control Release. 2000;65:403-18.

33. Dubey $\vee$, Mishra D, Jain NK. Melatonin loaded ethanolic liposomes: physicochemical characterization and enhanced transdermal delivery. Eur J Pharm Biopharm. 2007:67:398-405.

34. Paolino D, Lucania G, Mardente D, Alhaique F, Fresta M. Ethosomes for skin delivery of ammonium glycyrrhizinate: in vitro percutaneous permeation through human skin and in vivo anti-inflammatory activity on human volunteers. J Control Release. 2005;106:99-110.

35. Bishay P, Schmidt H, Marian C, Häussler A, Wijnvoord N, Ziebell S. RFlurbiprofen reduces neuropathic pain in rodents by restoring endogenous cannabinoids. PLoS One. 2010;5:10628.

36. Verma P, Prajapati SK, Yadav R, Senyschyn D, Shea PR, Trevaskis NL. Single intravenous dose of novel Flurbiprofen-loaded Proniosome formulations provides prolonged systemic exposure and anti-inflammatory effect. Mol Pharm. 2016;13:3688-99.

37. Naveed S, Sultana N, Arayne MS. In vivo interaction studies of lisinopril with flurbiprofen and ibuprofen on carrageenan induced inflammation. J Bioanal Biomed. 2014;6:1-4. 